\title{
Long non-coding RNA Fer-1-like family member 4 is overexpressed in human glioblastoma and regulates the tumorigenicity of glioma cells
}

\author{
FENG DING $^{1}$, HONGTU TANG ${ }^{2}$, DEKANG NIE ${ }^{3}$ and LIANG XIA ${ }^{4}$ \\ ${ }^{1}$ Department of General Surgery, Shandong Provincial Hospital Affiliated to Shandong University, Jinan, Shandong 250000; \\ ${ }^{2}$ Hubei Provincial Collaborative Innovation Center of Preventive Treatment by Acupuncture and Moxibustion, \\ College of Acupuncture and Moxibustion, Hubei University of Chinese Medicine, Wuhan, Hubei 430000; \\ ${ }^{3}$ Department of Neurosurgery, Yancheng First Peoples' Hospital, Yancheng, Jiangsu 224001; \\ ${ }^{4}$ Department of Neurosurgery, Zhejiang Cancer Hospital, Hangzhou, Zhejiang 310022, P.R. China
}

Received April 26, 2016; Accepted February 23, 2017

DOI: $10.3892 / \mathrm{ol} .2017 .6403$

\begin{abstract}
Long non-coding RNA (lncRNA) is a class of regulative non-coding RNA that is $>200$ nucleotides in length. Previous studies have demonstrated that lncRNA Fer-1-like family member 4 (FER1L4) serves regulatory roles in tumor progression; however, its clinical significance in human neuroglioma remains unclear. In the present study, data from The Cancer Genome Atlas was mined in order to investigate the association between FER1L4 expression and prognosis in patients with glioma. A short interfering (si)RNA targeting FER1L4 was transfected into U373-MG and U251 glioma cell lines, and cell viability, invasion and apoptosis were examined using CCK-8, Transwell and Annexin V-fluorescein isothiocyanate/propidium iodide assays, respectively. FER1L4 was significantly upregulated in high-grade glioma compared with low-grade glioma. Additionally, high expression of FER1L4 significantly predicted poor prognosis in patients with glioma. The expression of FER1L4 in glioma cell lines was significantly higher compared with that in normal astrocytes. Furthermore, by downregulating FER1L4 using siRNA, the invasiveness and viability of the glioma cells significantly decreased, while apoptosis significantly increased. The findings from the present study indicate that FER1L4 serves a role in the occurrence and progression of glioma, and could be used as a prognostic biomarker for this disease.
\end{abstract}

Correspondence to: Dr Dekang Nie, Department of Neurosurgery, Yancheng First Peoples' Hospital, 16 Yuehe Road, Yancheng, Jiangsu 224001, P.R. China

E-mail: famndk@163.com

Dr Liang Xia, Department of Neurosurgery, Zhejiang Cancer Hospital, 38 Guangji Road, Hangzhou, Zhejiang 310022, P.R. China E-mail: xialiang@zjcc.org.cn

Key words: long non-coding RNA, Fer-1-like family member 4, prognosis, biological function

\section{Introduction}

Neuroglioma is a primary nervous system tumor with a high rate of malignancy (1). Patients that receive surgical treatment for this disease typically have a poor prognosis, particularly those with glioblastoma multiforme (GBM), for which the average survival time is $<2$ years (2). According to a previous study (3), the occurrence and progression of glioma is associated with the abnormal expression of oncogenes and tumor suppressor genes. However, the molecular mechanisms underlying glioma development remain unclear (4). Investigating the association between changes in gene function and the occurrence and malignancy of glioma may aid in improving understanding of the molecular mechanisms underlying glioma development, and therefore the development of effective drugs to improve the survival of patients with this disease (5).

Long non-coding RNA (lncRNA) is a type of RNA that does not code for proteins and is $>200$ nucleotides in length $(6,7)$. LncRNAs regulate gene expression on an epigenetic, transcriptional and post-transcriptional level $(8,9)$. The modes by which lncRNAs regulate gene expression include chromosome modification and transcriptional activation or interference (10). Differential expression of lncRNA has been demonstrated between normal and cancerous tissues, such as lung cancer (11), colorectal cancer (12), breast cancer (13) and glioma (14), suggesting that abnormal lncRNA expression serves a role in tumor occurrence (15). LncRNA is a potential biomarker for predicting the outcomes of treatment and patient prognosis, and may be a target for gene therapy (16).

Fer-1-like family member 4 (FER1L4), a lncRNA, has been associated with tumor occurrence and progression, particularly in gastric and colon cancer $(17,18)$. In the present study, data from The Cancer Genome Atlas (TCGA) was mined in order to investigate the association between FER1L4 expression and the prognosis of patients with glioma. Reverse transcription-quantitative polymerase chain reaction (RT-qPCR) analysis was also performed to study the differential expression of FER1L4 in glioma cell lines and normal astrocytes. The results of the present study indicate that 
FER1L4 is a predictor of poor prognosis in glioma, and serves an important role in the occurrence and progression of glioma.

\section{Materials and methods}

Analysis of clinical data. The clinical data and gene array data for glioma in 149 patients with GBM, 158 patients with World Health Organization (WHO) II grade glioma and 177 patients with WHO III grade glioma was obtained from the TCGA database (19) using the platform illuminahiseq_rnaseqv2. All glioma samples were histologically graded in accordance with the 2007 WHO classification of tumors of the central nervous system (2). TCGA gene expression data for FER1L4 were extracted and merged with clinical outcome data for further analysis. The predictive value of FER1L4 on survival was examined, and FER1L4 expression acted as a continuous measurement in addition to a categorical variable. A total of 484 patients were divided into the following two groups according to FER1L4 expression with the median as the cutoff: High expression group (242 patients) and low expression group (242 patients).

Cell culture. Neuroglioma cell lines U373-MG, U251, LN-18, U87-MG and SHG-44 and the normal astrocyte cell line NHA-1800 were purchased from the Shanghai Institutes for Biological Sciences, Chinese Academy of Sciences (Shanghai, China). Fetal bovine serum (FBS), $0.25 \%$ trypsin and Dulbecco's modified Eagle's medium (DMEM) were purchased from Invitrogen (Thermo Fisher Scientific, Inc., Waltham, MA, USA). Other consumables for cell culture were purchased from BD Biosciences (Franklin Lakes, NJ, USA). The neuroglioma cell lines and the normal astrocyte cell line NHA-1800 were cultured in DMEM containing 10\% FBS and $1 \%$ myllicin at $37^{\circ} \mathrm{C}$ with $5 \% \mathrm{CO}_{2}$ in a humidified incubator. Cell passage was performed when the cells had grown to $80 \%$ confluence.

$R T-q P C R$. Total RNA extraction was performed using TRIzol reagent (Invitrogen; Thermo Fisher Scientific, Inc.), and RNA content was quantified using a UV-spectrophotometer (20). RNA was reverse transcribed to complementary (c)DNA using a RevertAid ${ }^{\mathrm{TM}}$ First Strand cDNA synthesis kit (Fermentas; Thermo Fisher Scientific, Inc.) and qPCR was performed. The primers were synthesized by Shanghai Invitrogen Biotechnology Co., Ltd. (Shanghai, China), and the sequences were as follows: FER1L4 forward, 5'CCG TGTTGAGGTGCTGTTC-3' and reverse, 5'GGCAAGTCC ACTGTCAGATG3'; GAPDH forward, 5'AAGGTGAAG GTCGGAGTCAA-3' and reverse, 5'AATGAAGGGGTC ATTGATGG-3'. The reaction components were as follows: DreamTaq $^{\mathrm{TM}}$ Green PCR Master Mix (2X) $10 \mu \mathrm{l}, 2 \mu \mathrm{l}$ PCR Forward Primer, $2 \mu 1$ PCR Reverse Primer, cDNA $2 \mu 1$, $\mathrm{ddH} 2 \mathrm{O} 4 \mu \mathrm{l}$. The thermocycling conditions were as follows: Denaturation at $95^{\circ} \mathrm{C}$ for $2 \mathrm{~min} ; 35$ cycles of $95^{\circ} \mathrm{C}$ for $30 \mathrm{sec}$, $57.4^{\circ} \mathrm{C}$ for $30 \mathrm{sec}, 72^{\circ} \mathrm{C}$ for $30 \mathrm{sec}$; and extension at $72^{\circ} \mathrm{C}$ for $10 \mathrm{~min}$. The PCR products were analyzed by $2 \%$ agarose gel electrophoresis. Gels were visualized by Gel $\mathrm{Doc}^{\mathrm{TM}} \mathrm{XR}$ gel documentation system (Bio-Rad Laboratories, Inc., Hercules, CA, USA). The $2^{-\Delta \Delta \mathrm{Cq}}$ method was used for the quantification of real-time RT-PCR gene products (21).
Transfection. A day prior to transfection, cells were seeded into a 6-well plate at a concentration of $4 \times 10^{5}$ cells/well. A total of $2 \mathrm{ml}$ DMEM containing 10\% FBS was added, and the cells were cultured $37^{\circ} \mathrm{C}$ with $5 \% \mathrm{CO}_{2}$ in the incubator overnight. Transfection was performed when the cells reached $70-80 \%$ confluence. For each well, $10 \mu 1$ Lipofectamine ${ }^{\circledR} 2000$ (Invitrogen; Thermo Fisher Scientific, Inc.) was added for every $4 \mu \mathrm{g}$ siRNA. For the negative control, the transfection was performed with a control siRNA, and serum-free medium was added. Culture medium was replaced $6 \mathrm{~h}$ following transfection. The short interfering (si)RNAs were provided by Shanghai Invitrogen Biotechnology Co., Ltd. (Shanghai, China). The siRNA sequences were as follows: FER1L4, 5'-CAGGACAGCUUCGAGUUAATT-3' for the forward, and control, 5'-UUCUCCGAACGUGUCACGUTT-3' for the forward.

Cell counting kit (CCK)-8 assay. The CCK-8 assay kit was purchased from Dojindo Molecular Technologies, Inc. (Kumamoto, Japan). Following transfection, logarithmic growth phase cells were harvested and seeded into a 96-well plate at a density of 5,000 cells/well, with 3 replicates for each group. At 24, 48, 72 and $96 \mathrm{~h}$ following transfection, $10 \mu \mathrm{l}$ CCK-8 solution was added into each well. The cells were then cultured at $37^{\circ} \mathrm{C}$ for $2 \mathrm{~h}$. Absorbance was measured for each well using a microplate reader at $450 \mathrm{~nm}$, and the growth status of cells in each group was compared.

Transwell assay. Matrigel-coated transwell cell culture chambers ( $8 \mu \mathrm{m}$ pore size) was purchased from EMD Millipore (Billerica, MA, USA). The Transwell plate was coated with Matrigel ${ }^{\circledR}$ (BD Biosciences) and placed into the incubator at $37^{\circ} \mathrm{C}$ to dry the basement membrane for $24 \mathrm{~h}$. Following transfection, a single-cell suspension $\left(5 \times 10^{4}\right)$ was added drop wise to the upper chamber and the cells were cultured for $24 \mathrm{~h}$ at $37^{\circ} \mathrm{C}$, cells on the upper surface of the filters were removed.

The filter membrane was fixed in $4 \%$ paraformaldehyde, and stained with Coomassie blue $(1 \mathrm{mg} / \mathrm{ml})$. The degree of invasion was quantified by counting the cells that migrated to the lower side of the filter in $\geq 5$ random fields using a light microscope.

Annexin V-fluorescein isothiocyanate (FITC)/propidium iodide (PI) apoptosis assay. An Annexin V-FITC/PI apoptosis kit was purchased from Nanjing KeyGen Biotech Co., Ltd (Nanjing, China). When the siRNA transfection cells reached $80 \%$ confluence following transfection they were digested with $0.25 \%$ trypsin and washed with pre-cooled PBS three times. The cells were suspended in $400 \mu \mathrm{l}$ binding buffer, and $5 \mu \mathrm{l}$ Annexin V-FITC was added into the cell suspension. Following gentle agitation, the cells were incubated at $2-8^{\circ} \mathrm{C}$ in the dark for $15 \mathrm{~min}$. A total of $10 \mu \mathrm{l} \mathrm{PI}$ was added, and the cells were incubated at $2-8^{\circ} \mathrm{C}$ in the dark for a further $5 \mathrm{~min}$. The cells were subsequently detected using a FACSCalibur (BD Biosciences, Franklin Lakes, NJ, USA) flow cytometer within $1 \mathrm{~h}$ and observed under a fluorescence microscope. The apoptotic analysis was performed using FlowJo (Tree Star, Inc., Ashland, OR, USA). Interpretation criteria were as follows: FITC-/PI- was defined as live cells in the lower left quadrant; $\mathrm{FITC}^{+} / \mathrm{PI}^{-}$was defined as late apoptotic cells in the 

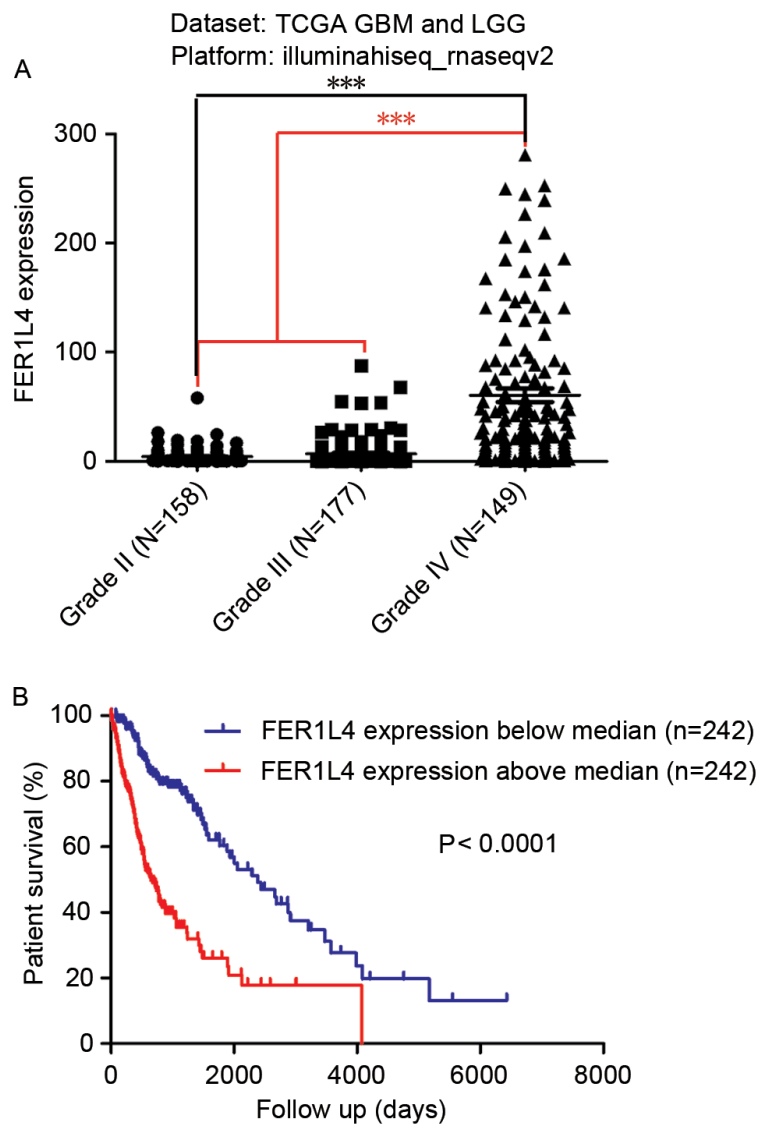

Figure 1. TCGA database results of the expression and prognostic significance of FER1L4 in patients with glioma. (A) FER1L4 expression levels in different grade glioma specimens. (B) Kaplan-Meier estimator survival curves for patients with glioma with high or low expression of FER1L4. ${ }^{* * * *} \mathrm{P}<0.001$. FER1L4, Fer-1-like family member 4; GBM, glioblastoma multiforme; LGG, low-grade glioma; TGCA, The Cancer Genome Atlas.

upper left quadrant; $\mathrm{FITC}^{+} / \mathrm{PI}^{+}$was defined as apoptotic cells in the upper right quadrant; FITC $^{+} / \mathrm{PI}^{-}$was defined as apoptotic cells in the lower right quadrant.

Statistical analysis. The results are presented as mean \pm standard deviation. Fisher's exact test and $\chi^{2}$ were used to compare clinicopathological data. One-way analysis of variance and two-sample t-tests were used to analysis the difference in lncRNA FER1L4 expression levels of different grade glioma tissues and four cell lines. The Kaplan-Meier estimator method was used to estimate overall survival, and a log-rank test was used to examine the differences between clinical characteristics and survival in patients with glioma. Analyses were performed using GraphPad Prism software (version 5; GraphPad Software, Inc., La Jolla, CA, USA), P-values less than 0.05 were regarded as statistically significant.

\section{Results}

High expression of FERIL4 predicts a poor prognosis in patients with glioma. To study the association between FER1L4 and glioma, the expression of FER1L4 in 484 patients with either GBM or LGG was analyzed by mining the TCGA database. The expression of FER1L4 in patients with grade IV glioma was $60.57 \pm 6.282(\mathrm{~N}=149)$, which was significantly
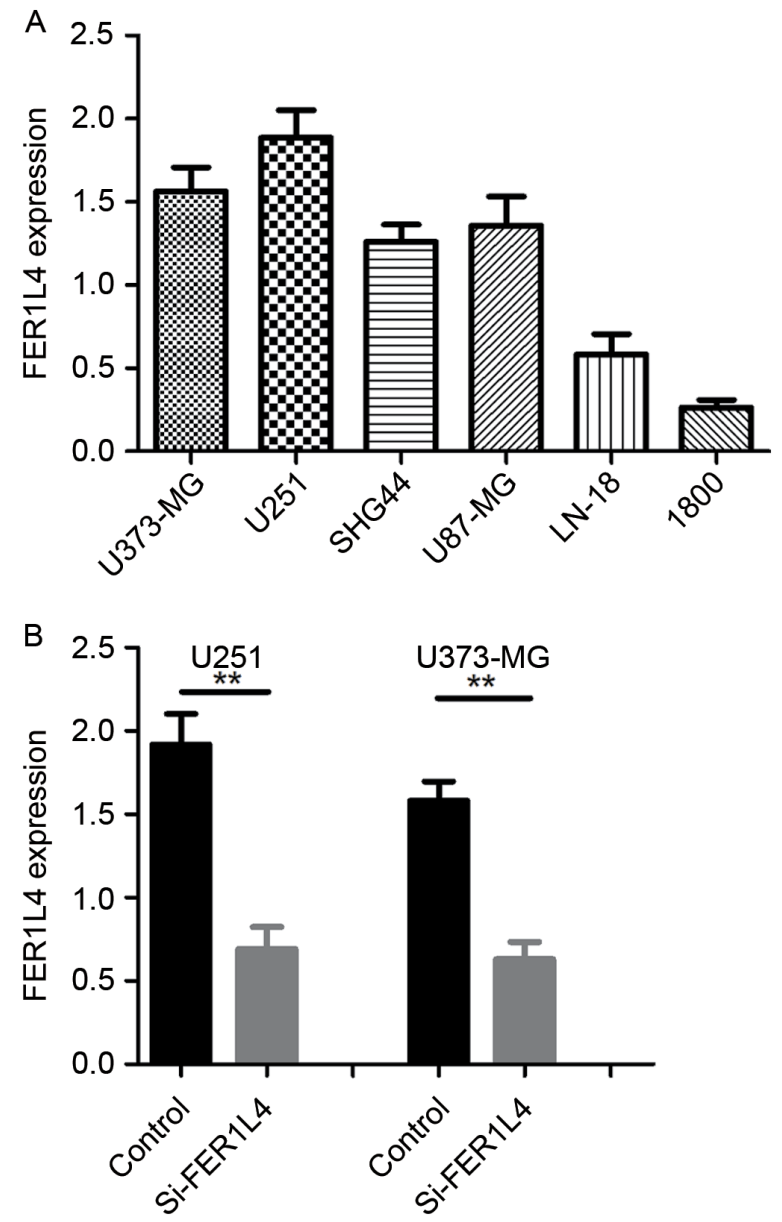

Figure 2. Expression of FER1L4 relative to GAPDH in glioma cell lines. (A) FER1L4 mRNA levels in different glioma cells (U373-MG, U251, U87-MG and SHG-44 and NHA-1800). (B) The expression of FER1L4 in si-FER1L4 U251/S373-MG cells and the controls $\left.{ }^{* *} \mathrm{P}<0.01\right)$. FER1L4, Fer-1-like family member 4; NHA-1800, normal astrocyte NHA-1800 cell line.

higher compared with that in patients with LGG (II-III; 5.754 $\pm 0.5195 ; \mathrm{N}=335)\left({ }^{* * *} \mathrm{P}<0.0001\right.$; Fig. 1A). In addition, the expression of FER1L4 in patients with grade III glioma (6.896 $\pm 0.8737 ; \mathrm{N}=177$ ) was significantly higher compared with that in patients with grade II glioma $(4.475 \pm 0.489 ; \mathrm{N}=158$; $\left.{ }^{* * * *} \mathrm{P}<0.0001\right)$. Survival analysis indicated that the prognosis of patients with high FER1L4 expression was significantly worse compared with those with low FER1L4 expression $(\mathrm{P}<0.0001$; Fig. 1B).

FERIL4 is highly expressed in glioma cell lines in vitro. RT-qPCR was performed to characterize the expression of FER1L4 in the glioma cell lines U373-MG, U251, U87-MG, SHG-44, LN-18 and in the normal astrocyte cell line NHA-1800. The results demonstrated that FER1L4 expression was higher in all the glioma cell lines studied compared with the normal astrocyte cells (Fig. 2A). The glioma cell lines U373-UG and U251 exhibited the highest FER1L4 expression (Fig. 2A).

Expression of FERIL4 is decreased following transfection with siRNA. In order to investigate the biological function of FER1L4 in glioma cells, U373-MG and U251 cells were 


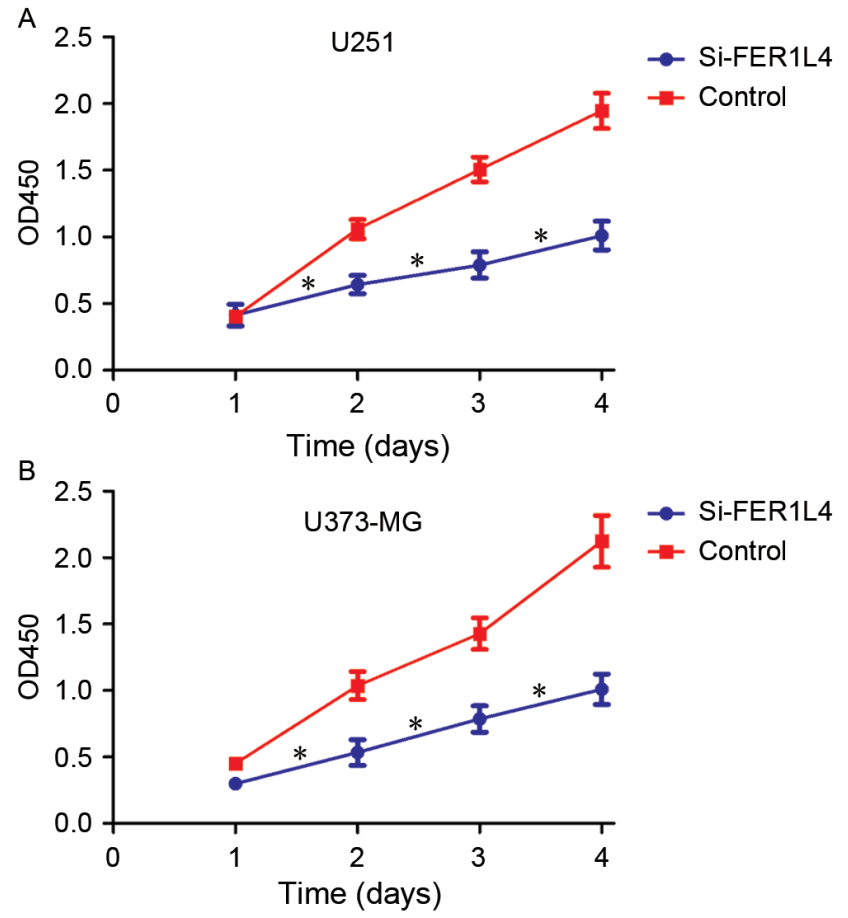

Figure 3. Effects of FER1L4 knockdown on the proliferation of glioma cells $\left({ }^{*} \mathrm{P}<0.05\right)$. A and $\mathrm{B}$, Growth curves indicating cell growth promotion by FER1L4(U251 and U373-MG). ${ }^{*}$ P $<0.05$.FER1L4,Fer-1-like family member4; OD, optical density; si, short interfering RNA.

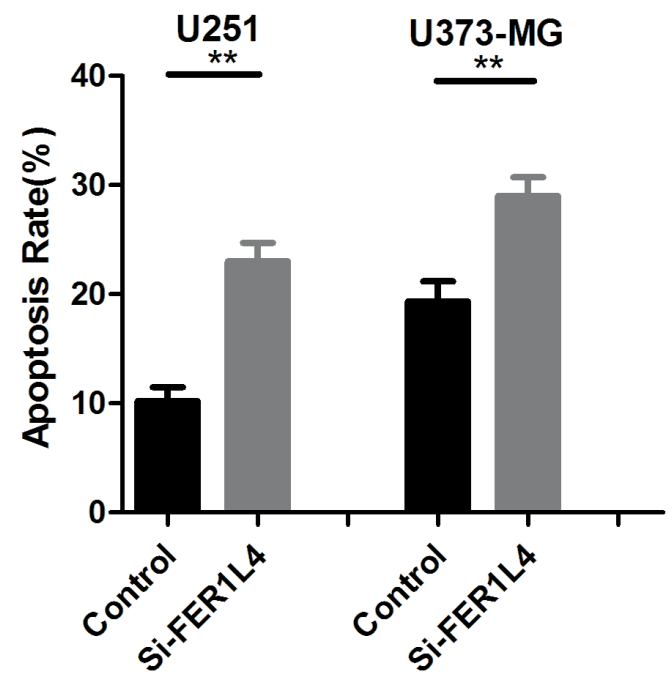

Figure 4. Effect of FER1L4 knockdown on the apoptosis of glioma cells. Apoptotic rates of cells detected in si-FER1L4 U251/S373-MG cells and the controls by using an Annexin-V-fluorescein isothiocyanate/propidium iodide analysis. ${ }^{* *} \mathrm{P}<0.01$. FER1L4, Fer-1-like family member 4; si, short interfering RNA.

transfected with siRNA directed against FER1L4. At $48 \mathrm{~h}$ following transfection, FER1L4 expression was significantly downregulated in si-FER1L4-treated cells compared with the control cells (treated with control siRNA) (Fig. 2B).

Detection of cell proliferation, apoptosis and invasion. CCK-8 and Transwell assays were performed following transfection with FER1L4 siRNA in order to investigate the association
A

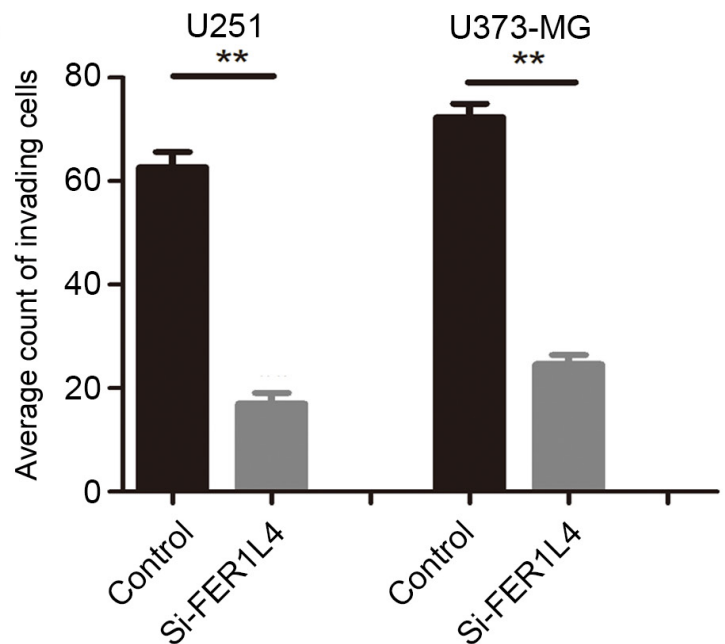

B
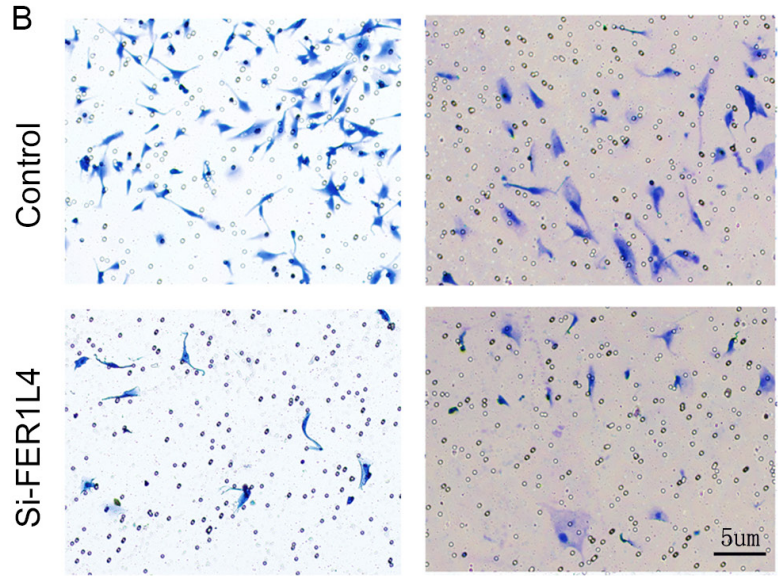

U251

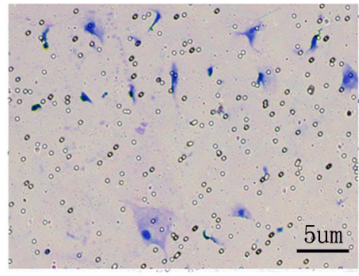

U373-MG

Figure 5. FER1L4 knockdown inhibits the invasion of U373-MG and U251 cells. (A) Quantification (average cell count) of invading cells in si-FER1L4 U251/S373-MG cells and the control from a Transwell assay. (B) Representative images of invading cells. ${ }^{* *} \mathrm{P}<0.01$. FER1L4, Fer-1-like family member 4; si, short interfering RNA.

between FER1L4 expression and glioma viability and invasion, respectively. Flow cytometry was performed to detect changes in the apoptosis of glioma cells. The survival rates of the FER1L4 siRNA-treated glioma cells (U251 or U373-MG) were significantly lower compared with that of the control cells $(\mathrm{P}<0.05$; Fig. 3), and the percentage of apoptotic si-FER1L4 glioma cells was significantly higher compared with that of the control cells $(\mathrm{P}<0.01$; Fig. 4). The Transwell assay revealed that the number of si-FER1L4-treated glioma cells penetrating the basement membrane in each field of view was significantly lower compared with that of the control cells ( $\mathrm{P}<0.0001$; Fig. 5).

\section{Discussion}

Studies that investigate the underlying molecular mechanisms of neuroglioma pathogenesis, and identify novel treatments and targets for gene therapy are required to improve the prognosis of patients with neuroglioma (22). LncRNAs, including maternally expressed 3 (MEG3) and H19 imprinted maternally expressed transcript (H19) have been associated with the occurrence and progression of neuroglioma (23-25). 
MEG3 was the first lncRNA demonstrated to have a tumor suppressor effect, and is typically upregulated in tumor tissues compared with normal tissues (26); however, a previous study demonstrated that MEG3 is either not expressed or markedly downregulated in $82 \%$ of patients with glioma (24). The activity of cellular tumor antigen p53 is regulated through the downregulation of MEG3, which creates favorable conditions for the in vitro growth of glioma cells (24). MEG3 may regulate the occurrence and progression of glioma, and therefore represents a novel target for gene therapy (27).

H19 was one of the earliest lncRNAs to be identified and is highly expressed in the embryonic stages of development. H19 is primarily expressed in endoderm- and mesoderm-derived tissues and belongs to the maternally-derived imprinted gene family (28). A previous study suggested that $\mathrm{H} 19$ serves a role as an oncogene and a tumor suppressor gene (28). Shi et al (25) discussed the potential biological functions of $\mathrm{H} 19$ in glioma. H19 expression was associated with glioma stage; the expression of H19 and its derivative microRNA, miR-675, in high-grade glioma was significantly higher compared with that in low-grade glioma. As H19 was downregulated, miR-675 was also downregulated. H19 is the precursor of miR-675, and H19's oncogenic and regulatory effects on the invasiveness of glioma cells are achieved through miR-675 and the inhibition of cadherin-13 (25). In addition, H19 regulates the activity of transcriptional factor zinc finger protein GLI1 (GLI1), which serves a role in the development of astrocytoma. Abnormally high expression of GLI1 is typically detected in brain glioma, and the upregulation of GLI1 is associated with an increased cell proliferation index, pathology index and the recurrence of glioma (29).

FER1L4 has primarily been studied in gastric and colon cancer $(17,18)$. Liu et al (30) demonstrated that FER1L4 was downregulated in $91.80 \%$ of gastric cancer tissues studied. Additionally, low expression of FER1L4 was associated with tumor size, histological staging, tumor infiltration depth, lymph node metastasis, distant metastasis, tumor-node-metastasis staging, angioneurotic infiltration and serum CA72-4 antigen levels. The expression of FER1L4 is a diagnostic indicator for gastric cancer at an early stage (30). A subsequent study demonstrated that FER1L4 is a competing endogenous RNA that acts as a tumor suppressor in colon cancer (18), where its expression is negatively correlated with miR-106a-5p expression. The expression levels of FER1L4 and miR-106a-5p are correlated with tumor infiltration, lymph node metastasis, vascular infiltration and clinical staging in colon cancer. By increasing the expression of FER1L4 exogenously, miR-106a-5p expression can be downregulated, thus reducing the proliferation, migration and invasion of colon cancer (18).

In the present study, the expression of FER1L4 in patients with different grade of glioma was investigated by mining TCGA data. FER1L4 was significantly upregulated in patients with high-grade glioma compared with patients with LGG, and high expression of FER1L4 significantly predicted a poor prognosis for patients with glioma. Therefore, FER1L4 may be a prognostic indicator for glioma. Additionally, glioma cell invasion and viability were significantly inhibited by transfection with a FER1L4 siRNA, which promoted apoptosis. These results suggest that FER1L4 has a cancer-promoting effect in glioma and is a novel target for gene therapy. However, further studies are required to investigate the underlying molecular mechanisms of the roles that FER1L4 serves in glioma.

\section{Acknowledgements}

The present study was supported by the National Natural Science Foundation of China (grant no. 81502147), Zhejiang Medical Science and Technology Project (2017194140) and the Youth Scientific Innovation Foundation of Zhejiang Cancer Hospital (grant no. QN201402).

\section{References}

1. Soffietti R, Bertero L, Pinessi L and Rudà R: Pharmacologic therapies for malignant glioma: A guide for clinicians. CNS Drugs 28: 1127-1137, 2014.

2. Morgan LL: The epidemiology of glioma in adults: A 'state of the science' review. Neuro Oncol 17: 623-624, 2015.

3. Bai H, Harmanc AS, Erson-Omay EZ, Li J, Coşkun S, Simon M, Krischek B, Özduman K, Omay SB, Sorensen EA, et al: Integrated genomic characterization of IDH1-mutant glioma malignant progression. Nat Genet 48: 59-66, 2016.

4. Simonetti G, Gaviani P, Innocenti A, Botturi A, Lamperti E and Silvani A: Update on treatment strategies for anaplastic glioma: A review of literature. Neurol Sci 35: 977-981, 2014.

5. Wang $\mathrm{Y}$ and Jiang T: Understanding high grade glioma: Molecular mechanism, therapy and comprehensive management. Cancer Lett 331: 139-146, 2013.

6. Spizzo R, Almeida MI, Colombatti A and Calin GA: Long non-coding RNAs and cancer: A new frontier of translational research? Oncogene 31: 4577-4587, 2012.

7. Wapinski $\mathrm{O}$ and Chang HY: Long noncoding RNAs and human disease. Trends Cell Biol 21: 354-361, 2011.

8. ENCODE ProjectConsortium; Birney E,Stamatoyannopoulos JA, Dutta A, Guigó R, Gingeras TR, Margulies EH, Weng Z, Snyder M, Dermitzakis ET, et al: Identification and analysis of functional elements in $1 \%$ of the human genome by the ENCODE pilot project. Nature 447: 799-816, 2007.

9. Derrien T, Johnson R, Bussotti G, Tanzer A, Djebali S, Tilgner H, Guernec G, Martin D, Merkel A, Knowles DG, et al: The GENCODE $\mathrm{v} 7$ catalog of human long noncoding RNAs: Analysis of their gene structure, evolution, and expression. Genome Res 22: 1775-1789, 2012.

10. Tsai MC, Manor O, Wan Y, Mosammaparast N, Wang JK, Lan F, Shi Y, Segal E and Chang HY: Long noncoding RNA as modular scaffold of histone modification complexes. Science 329: 689-693, 2010.

11. Wan L, Zhang L, Fan K, Cheng ZX, Sun QC and Wang JJ: Knockdown of long noncoding RNA PCAT6 inhibits proliferation and invasion in lung cancer cells. Oncol Res 24: 161-170, 2016.

12. Thorenoor N, Faltejskova-Vychytilova P, Hombach S, Mlcochova J, Kretz M, Svoboda $M$ and Slaby O: Long non-coding RNA ZFAS1 interacts with CDK1 and is involved in p53-dependent cell cycle control and apoptosis in colorectal cancer. Oncotarget 7: 622-637, 2016.

13. Mendell JT: Targeting a long noncoding RNA in breast cancer. $\mathrm{N}$ Engl J Med 374: 2287-2289, 2016.

14. Reon BJ, Anaya J, Zhang Y, Mandell J, Purow B, Abounader R and Dutta A: Expression of lncRNAs in low-grade gliomas and glioblastoma multiforme: An in silico analysis. PLoS Med 13: e1002192, 2016.

15. Cabili MN, Trapnell C, Goff L, Koziol M, Tazon-Vega B, Regev A and Rinn JL: Integrative annotation of human large intergenic noncoding RNAs reveals global properties and specific subclasses. Genes Dev 25: 1915-1927, 2011.

16. Huarte $\mathrm{M}$ and Rinn JL: Large non-coding RNAs: Missing links in cancer? Hum Mol Genet 19: R152-R161, 2010.

17. Song H, Sun W, Ye G, Ding X, Liu Z, Zhang S, Xia T, Xiao B, $\mathrm{Xi} Y$ and Guo J: Long non-coding RNA expression profile in human gastric cancer and its clinical significances. J Transl Med 11: 225, 2013.

18. Yue B, Sun B, Liu C, Zhao S, Zhang D, Yu F and Yan D: Long non-coding RNA Fer-1-like protein 4 suppresses oncogenesis and exhibits prognostic value by associating with miR-106a-5p in colon cancer. Cancer Sci 106: 1323-1332, 2015. 
19. Ceccarelli M, Barthel FP, Malta TM, Sabedot TS, Salama SR, Murray BA, Morozova O, Newton Y, Radenbaugh A, Pagnotta SM, et al: Molecular profiling reveals biologically discrete subsets and pathways of progression in diffuse glioma. Cell 164: 550-563, 2016.

20. Dehghani Mohammad Abadi M, Ashraf N, Chamsaz M and Shemirani F: An overview of liquid phase microextraction approaches combined with UV-Vis spectrophotometry. Talanta 99: 1-12, 2012.

21. Regier N and Frey B: Experimental comparison of relative RT-qPCR quantification approaches for gene expression studies in poplar. BMC Mol Biol 11: 57, 2010.

22. Hamza MA and Gilbert M: Targeted therapy in gliomas. Curr Oncol Rep 16: 379, 2014.

23. Argyriou AA and Kalofonos HP: Molecularly targeted therapies for malignant gliomas. Mol Med 15: 115-122, 2009.

24. Wang P, Ren Z and Sun P: Overexpression of the long non-coding RNA MEG3 impairs in vitro glioma cell proliferation. J Cell Biochem 113: 1868-1874, 2012.

25. Shi Y, Wang Y, Luan W, Wang P, Tao T, Zhang J, Qian J, Liu N and You Y: Long non-coding RNA H19 promotes glioma cell invasion by deriving miR-675. PLoS One 9: e86295, 2014.
26. Zhou Y, Zhang X and Klibanski A: MEG3 noncoding RNA: A tumor suppressor. J Mol Endocrinol 48: R45-R53, 2012.

27. Li J, Bian EB, He XJ, Ma CC, Zong G, Wang HL and Zhao B: Epigenetic repression of long non-coding RNA MEG3 mediated by DNMT1 represses the p53 pathway in gliomas. Int J Oncol 48: 723-733, 2016.

28. Ariel I, de Groot $\mathrm{N}$ and Hochberg A: Imprinted H19 gene expression in embryogenesis and human cancer: The oncofetal connection. Am J Med Genet 91: 46-50, 2000.

29. Tchoghandjian A, Baeza-Kallee N, Beclin C, Metellus P, Colin C, Ducray F, Adélaïde J, Rougon G and Figarella-Branger D: Cortical and subventricular zone glioblastoma-derived stem-like cells display different molecular profiles and differential in vitro and in vivo properties. Ann Surg Oncol 19 (Suppl 3): S608-S619, 2012.

30. Liu Z, Shao Y, Tan L, Shi H, Chen S and Guo J: Clinical significance of the low expression of FER1L4 in gastric cancer patients. Tumour Biol 35: 9613-9617, 2014. 